\title{
Circulating Interleukin-6 (but Not Other Immune Mediators) Associates with Criteria for Fried's Frailty among Very Old Adults
}

\author{
Gilberto Santos Morais Junior $\left(\mathbb{D},{ }^{1}\right.$ Diego Ignacio Valenzuela Perez $(\mathbb{D}){ }^{2}$ \\ Audrey Cecília Tonet-Furioso $\left(\mathbb{D},{ }^{3}\right.$ Lucy Gomes, ${ }^{3}$ Karla Helena Coelho Vilaça ${ }^{(D)}{ }^{3}$ \\ Vicente Paulo Alves $\mathbb{D},{ }^{3}$ Clayton Franco Moraes $\mathbb{D}^{1,3}$ and Otávio Toledo Nóbrega $\mathbb{D}^{1,4}$ \\ ${ }^{1}$ Health Faculty, Campus Universitário Darcy Ribeiro, Universidade de Brasília, Brasília, DF, Brazil \\ ${ }^{2}$ Kinesiology School and Physical Activity and Sports Science Master Program, Universidad Santo Tomás, Puerto Montt, Chile \\ ${ }^{3}$ Graduate Program in Gerontology, Campus Taguatinga, Universidade Católica de Brasília, Brasília, DF, Brazil \\ ${ }^{4}$ Division of Geriatric Medicine, Department of Medicine, McGill University, 1001 Boul Décarie, Montreal, QC, Canada
}

Correspondence should be addressed to Otávio Toledo Nóbrega; otnobrega@gmail.com

Received 3 June 2020; Revised 8 October 2020; Accepted 22 October 2020; Published 4 November 2020

Academic Editor: Giulia Accardi

Copyright (c) 2020 Gilberto Santos Morais Junior et al. This is an open access article distributed under the Creative Commons Attribution License, which permits unrestricted use, distribution, and reproduction in any medium, provided the original work is properly cited.

\begin{abstract}
Background and Aim. Frailty is a geriatric condition resulting from physiological changes covering the musculoskeletal, immune, and neuroendocrine systems, leading to a greater inflammatory state. The present research aimed to investigate the association of components of Fried's frailty (as well as of the phenotype as a whole) with total serum levels of a panel of inflammatory mediators. Methods. One hundred and sixty-one very old patients (aged $\geq 80$ years) devoid of cognitive decline were eligible for analyses. Clinical and biochemical data along with physical and cognitive assessments encompassing dual-energy X-ray scans and hand dynamometry were adopted to investigate frailty criteria, while circulating immune mediators $(I F N \gamma, I L-2, I L-4, I L-6, I L-10$, and $T N F \alpha$ ) were assessed using high-throughput flow cytometry. Results. Preliminarily, IL-6 correlated positively with waist-to-hip ratio and C-reactive protein and negatively with glycemia. In analyses controlled for these factors, serum levels of IL-6 were comparatively augmented among the very old participants with reduced grip strength $(\mathrm{OR}=3.299 ; 95 \%$ CI $1.08-6.09 ; p=0.032)$ and among those with slow walk speed $(\mathrm{OR}=2.460 ; 95 \% \mathrm{CI} 1.16-7.05 ; p=0.022)$. Conclusions. Our study shows a strong negative correlation of $I L-6$ levels with Fried's frailty components of grip strength and walk speed in very old adults, regardless of confounding factors.
\end{abstract}

\section{Introduction}

The aging process is responsible for dysfunctions in skeletal muscles, strength, and bone mass and increases the risk of disability especially among very old adults [1-3]. Frailty is a geriatric condition resulting from physiological changes that affect the musculoskeletal, immune, and neuroendocrine systems [4], leading to functional decline in elderly population and increasing prevalence of chronic degenerative diseases, depression, and mortality [5-7].

Studies point to a greater risk of negative events in terms of health and functionality among the very old ( $\geq 80$ years) subset of older individuals with the syndrome, with evidence that frailty in this stratum contributes to increased mortality related to falls $[8,9]$. Despite that, the fundamental characteristics of frailty are well established on the basis of declines in lean body composition as well as loss in muscular endurance and performance, and the pathophysiological changes that underlie this clinical entity are still not well understood. In this context, a process entitled as "inflammageing" that usually refers to slightly, subclinically higher levels of serum immune mediators in older adults relative to youngsters, both groups devoid of overt infectious disease, is associated with the pathophysiology of chronic conditions such as frailty [10-12] and susceptibility to infectious illnesses such as COVID-19 [13]. Enhanced levels of circulating 
immune mediators such as IL-6 are often taken as a surrogate for "inflammageing" and are consistently associated with the frail phenotype and mortality $[10,14]$.

A proinflammatory context is understood as a strong contributor to the onset of frailty [15-17], and mediators such as interferon gamma (IFN $\gamma$ ) and tumor necrosis factor alpha (TNF $\alpha$ ) have already been implicated with the development of the syndrome $[17,18]$. There is evidence that anti-inflammatory interleukins (ILs) such as $I L-10$ and $I L-4$, although implicated to a lesser extent, also associate with the frailty phenotype [19-21]. However, among all known mediators, IL-6 appears to play a prominent role in pathophysiology of the condition $[16,22]$, with direct evidence in favor of high levels of the mediator as well as of C-reactive protein $(\mathrm{C}-\mathrm{RP})$ in the onset of frailty [23-25], possibly due to its extra-immune effects on protein degradation and related metabolic pathways [26].

Each isolate component of frailty per se represents a domain of importance to the overall health and functionality of the oldest old. Hand grip strength, for instance, is an important marker of morbidity and mortality [27], and series of reports have demonstrated that low performance correlates with higher levels of subclinical inflammation [28-30]. Also, other reports have associated augmented serum concentrations of $I L-6$ with lower gait speed and reduced muscle strength in a context of frailty [31-34]. Thus, the present study aimed to investigate a possible association of frailty components (as well as of the phenotype itself) with total serum levels of a broad, comprehensive panel of inflammatory mediators evaluated in a sample of very old Brazilian patients.

\section{Materials and Methods}

2.1. Study Design. The present study has a cross-sectional analytical nature and has enrolled very old frail and nonfrail participants living in Brasília, Federal District, Brazil.

2.2. Sample. A sample of 161 elderly, nondemented individuals aged $\geq 80$ years was constituted based on patients that regularly and electively attended health care services for older adults in the Brazilian Federal District, Brazil (Figure 1). The elderly were characterized as carriers or not of frailty based on the criteria developed by Fried et al. [4]. All participants signed a free and informed consent form to participate in the research. Inclusion criteria consisted of being 80 years of age or older and not having mobility or cognitive problems. Exclusion criteria were based on recommendations by Ferruci et al. [35], namely, having important cognitive deficits (including Parkinson's or Alzheimer's diseases), detectable sensory deficit (especially in vision), active clinical condition with immunological impact (infection, autoimmunity, or malignancy), and regular use of immunomodulatory drugs in the last 30 days. Clinical evaluation of each patient was according to basic procedures of semiology and semiotics, with diagnosis of the most prevalent clinical conditions performed according to guidelines of specialized societies taking into account the history of diseases and consumption of drugs as described in medical records or self-reported [36]. Cognitive decline was investigated based on criteria of the American Psychiatric Association (APA/DSM-IV) and of the Alzheimer's Disease Assessment Scale-Cognitive Subscale (ADAS-Cog) for investigation of suspected cases of dementia [37]. This study followed the recommendations of the Declaration of Helsinki and was approved by the Research Ethics Committee of Catholic University of Brasilia, under registry number 50075215.2.0000.0029.

2.3. Blood Collection. Initially, blood drawn by venipuncture was obtained by trained nursing professionals, yielding serum samples by centrifugation at 2,500 rpm for $15 \mathrm{~min}$ that were processed immediately for clinical biochemistry by one same laboratory. For the analysis of the inflammatory panel, serum samples were quickly stored at $-80^{\circ}$ for later evaluations.

2.4. Anthropometric and Biochemical Measures. The anthropometric measurements obtained consisted of body mass $(\mathrm{kg})$ and height $(\mathrm{m})$ as well as circumferences of the waist (WC) and hip (QC), with which body mass indexes (BMI) and waist-to-hip (W-H) ratios were calculated based on WHO recommendations [38]. Measurements of body fat percentage $(\% F)$ and bone mineral density (BMD) were obtained with double-energy X-ray absorptiometry (DXA) and model DPX-IQ (GE Lunar Corporation) of the pencil beam type operated according to manufacturer's recommendations with data analyzed with software version 4.7.

Clinical biochemistry analyses were performed following laboratory protocols and quality control steps compatible with routine practices. Levels of glucose, triglycerides, total cholesterol, and fractions were measured by enzymatic, kinetic, or colorimetric tests (as appropriate) with reagents compatible with the HumanStar 600 equipment (InVitro ${ }^{\circledR}$ ). LDL was estimated according to Martin's formula [39]. The same automatized platform was used to determine levels of ultrasensitive C-reactive protein and glycated hemoglobin by turbidimetry and ion-exchange high-performance liquid chromatography, respectively.

2.5. Frailty Characterization. Physical activity was measured by self-report using a translated version of the Minnesota Leisure Time Activities Questionnaire, validated for the Brazilian Portuguese [40]. Exhaustion was also measured by self-report using items 7 and 20 of the Center for Epidemiological Studies Scale for Depression-CES-D [41]. The hand grip strength was measured using a hydraulic dynamometer (Jamar brand, Model 5030J1, Lafayette Instruments Inc.) through three runs with one minute of rest between attempts and a final score determined as average of all attempts [42]. Finally, walking time was measured using the $4.6 \mathrm{~m}$ test, based on recommendations of Guralnik et al. [43], with the final score as an average of three runs [44].

Frailty was defined based on the criteria proposed by Fried et al. [4] and adapted by the Network of Studies on 


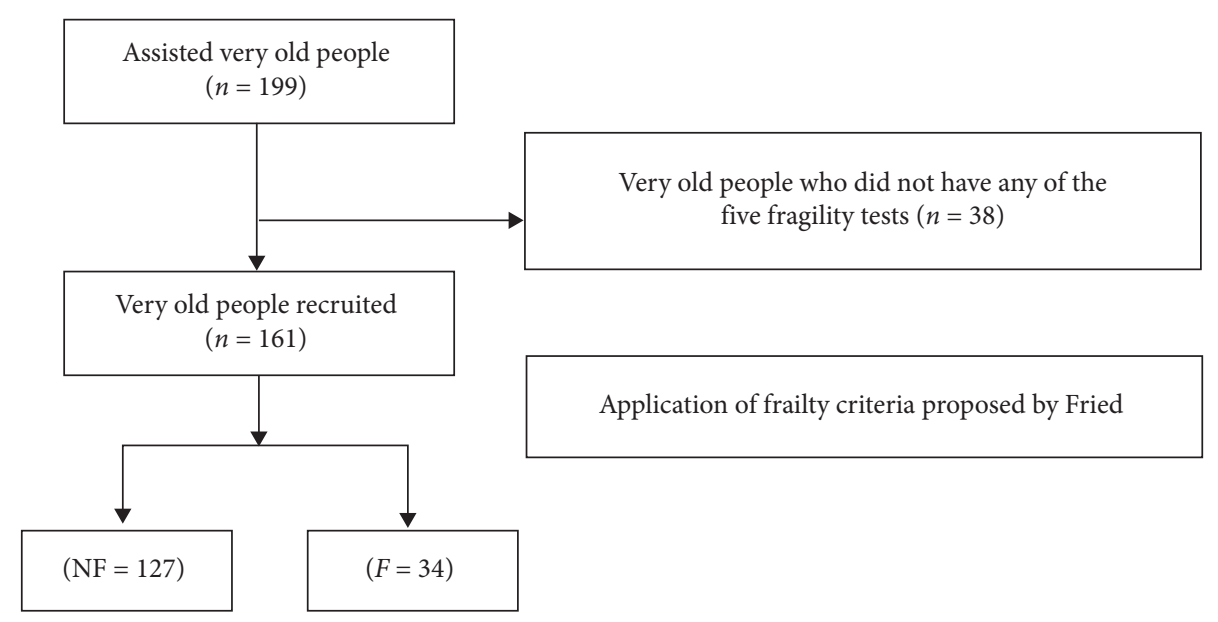

Figure 1: A schematic drawing of the sample. $\mathrm{NF}=$ nonfrail and $F=$ frail.

Frailty in Elderly Brazilians (FIBRA) [44, 45], comprising five stages. Weight loss was defined as a reduction of $\geq 4.5 \mathrm{~kg}$ or $\geq 5 \%$ of body weight in the last year. Exhaustion was excessive lack of fitness to perform tasks of daily living, with a participant unable to perform tasks for more than three consecutive days. Women scored for low activity if showing weekly energy expenditure $<270 \mathrm{kcal}$, whereas men if with weekly energy expenditure $<383 \mathrm{kcal}$. Participants who performed among the $20 \%$ lower levels of grip strength and among those within the $20 \%$ with higher values of walking time (adjusted for sex, BMI, or height, as appropriate) scored for frailty.

2.6. Inflammatory Profile. Inflammatory profile was assessed using high-throughput flow cytometry (FACS Verse model; BD Biosciences, San Jose, CA, USA) with the serum previously collected and the Human Th1/Th2 cytokine kit as reagent (BD Biosciences) to assess six mediators: $I F N \gamma, I L-2$, $I L-4, I L-6, I L-10$, and TNF $\alpha$. The reactions were performed following the manufacturer's protocol, producing a titration curve with standards provided by the kit. All scores were estimated by interpolation of the respective curve. Whenever a given sample yielded out of range of outlying readings, the assay was repeated with an original or diluted sample (as necessary) until a minimum of three hundred events were acquired for each type of cytokine bead used. All data were analyzed using FCAP software, version 3.0 (BD Biosciences).

2.7. Statistical Analysis. Initially, the Kolmogorov-Smirnov test was performed to observe data distribution. Student's $t$ test for independent samples was used for anthropometric data, whereas the nonparametric Mann-Whitney test was used for biochemical data and inflammatory profile, and the chi-square test was employed for categorical variables. Data with normal distribution are expressed as mean and standard deviation, while data with non-normalized dispersion are shown as median and interquartile range, and categorical data are indicated in proportions. After initial analyses, a logarithmic transformation of the inflammatory profile was performed, followed by Pearson's correlation analyses between these log-transformed inflammatory measures and scores of clinical/biochemical characteristics and of each component of the frailty syndrome. Univariate and multivariate analyses were performed by binary logistic regression, with the aim of analyzing association of isolate frailty components (as well as of the phenotype as a whole) with each immune marker. For construction of a multivariate model, variables that obtained $p<0.20$ in univariate analysis were considered. All analyses were performed using SPSS Software, version 22 .

\section{Results}

Of the 161 very old adults, 127 were characterized as nonfrail while 34 were identified as carriers of the syndrome (Figure 1). Anthropometric, biochemical, and clinical characteristics are shown in Table 1, according to the frailty status. There was no significant difference in anthropometric and biochemical profile between groups.

To assess which clinical and metabolic conditions of the sample could interfere with main models of association between inflammatory mediators and frailty components, correlation tests were run with the circulating levels of each cytokine across the anthropometric measures as well as the biochemical variables. In these tests, $I L-6$ showed a positive correlation with $W$ - $R$ ratio and with levels of $C-R P$, as well as a negative correlation with glycemia. No other cytokine was found to correlate with the clinical traits assessed (Table 2).

To estimate to which proportion inflammatory mediators could be found in unequal quantities according to each component of Fried's frailty (or to the phenotype as a whole), univariate models of binary logistic regression were tested. In these calculations, covariates that showed a previous correlation with $I L-6$ (Table 2) were included so as to control analyses for confounding variables ( $W-H$ ratio, glucose, and $C-R P)$. With this approach, only the grip strength component was associated with the variables included in the model $\left[\chi^{2}(4)=12.217 ; p=0.016, R^{2}=0.134\right]$. As a result, the very old participants with a level of strength compatible with frailty showed an almost 4.7-fold greater chance of having IL-6 titers higher than those found with the 
TABLe 1: Anthropometric and metabolic characteristics of the sample according to clinical condition.

\begin{tabular}{|c|c|c|c|}
\hline & Nonfrailty $(n=127)$ & Frailty $(n=34)$ & $p$ \\
\hline Age (years)* & $84.3 \pm 4.1$ & $84.5 \pm 4.0$ & 0.800 \\
\hline Body mass $(\mathrm{Kg})^{*}$ & $64.0 \pm 12.7$ & $62.9 \pm 11.6$ & 0.663 \\
\hline Height $(\mathrm{m})^{*}$ & $1.6 \pm 0.1$ & $1.5 \pm 0.1$ & 0.314 \\
\hline BMI $\left(\mathrm{kg} \cdot \mathrm{m}^{-2}\right)^{*}$ & $26.1 \pm 4.6$ & $26.3 \pm 4.0$ & 0.748 \\
\hline Body fat $(\%)^{*}$ & $32.6 \pm 9.9$ & $32.7 \pm 9.1$ & 0.975 \\
\hline $\mathrm{WC}(\mathrm{cm})^{*}$ & $92.9 \pm 12.2$ & $95.4 \pm 12.7$ & 0.338 \\
\hline $\mathrm{HC}(\mathrm{cm})^{*}$ & $99.9 \pm 9.7$ & $99.8 \pm 9.2$ & 0.967 \\
\hline W-H ratio ${ }^{*}$ & $0.9 \pm 0.1$ & $1.0 \pm 0.1$ & 0.128 \\
\hline MMSE (score)* & $20.7 \pm 6.5$ & $18.5 \pm 6.3$ & 0.087 \\
\hline Glucose $(\mathrm{mg} / \mathrm{dL})^{* *}$ & $93.0(87.0-105.0)$ & $94.0(78.5-105.5)$ & 0.541 \\
\hline $\mathrm{TC}\left(\mathrm{mg} \cdot \mathrm{dl}^{-1}\right)^{* *}$ & $184.0(163.0-208.0)$ & $180.0(159.2-186.5)$ & 0.117 \\
\hline HDL-c $\left(\mathrm{mg} \cdot \mathrm{dl}^{-1}\right)^{* *}$ & $50.0(41.0-56.0)$ & $50.0(42.8-57.0)$ & 0.639 \\
\hline LDL-c $\left(\mathrm{mg} \cdot \mathrm{dl}^{-1}\right)^{* *}$ & $109.0(87.0-131.0)$ & $104.5(83.0-115.5)$ & 0.084 \\
\hline TG $\left(\mathrm{mg} \cdot \mathrm{dl}^{-1}\right)^{* *}$ & $125.0(97.0-152.0)$ & $129.0(91.8-148.2)$ & 0.988 \\
\hline C-RP $\left(\mathrm{mg} \cdot \mathrm{dl}^{-1}\right)^{* *}$ & $0.4(0.4-0.4)$ & $0.4(0.4-0.7)$ & 0.511 \\
\hline $\operatorname{HbAlc}\left(\mathrm{mg} \cdot \mathrm{dl}^{-1}\right)^{* *}$ & $5.7(5.5-6.1)$ & $5.8(5.5-6.2)$ & 0.954 \\
\hline $\mathrm{IFN} \gamma(\mathrm{pg} / \mathrm{ml})^{* *}$ & $5.9(5.4-6.6)$ & $5.5(4.9-6.5)$ & 0.283 \\
\hline $\mathrm{TNF} \alpha(\mathrm{pg} / \mathrm{ml})^{* *}$ & $1.7(1.1-2.4)$ & $1.7(1.0-2.6)$ & 0.987 \\
\hline IL-10 (pg/ml $)^{* *}$ & $3.4(2.9-4.0)$ & $3.3(2.8-3.8)$ & 0.615 \\
\hline IL-6 (pg/ml) ${ }^{* *}$ & $4.7(3.5-8.8)$ & $6.4(3.8-12.8)$ & 0.350 \\
\hline $\mathrm{IL}-4(\mathrm{pg} / \mathrm{ml})^{* *}$ & $1.7(1.3-2.1)$ & $1.6(1.0-1.9)$ & 0.192 \\
\hline IL-2 $(\mathrm{pg} / \mathrm{ml})^{* *}$ & $9.0(8.6-9.9)$ & $9.3(8.6-9.8)$ & 0.546 \\
\hline Grip strength $(\mathrm{kgf})^{* *}$ & $18.6(14.0-24.6)$ & $16.1(13.6-18.7)$ & 0.041 \\
\hline Walking time $(\mathrm{s})^{* *}$ & $5.0(4.3-6.7)$ & $7.0(5.6-8.8)$ & 0.001 \\
\hline Current diabetes $(\%)^{\dagger}$ & 27.0 & 40.0 & 0.173 \\
\hline Current SAH $(\%)^{\dagger}$ & 80.2 & 87.5 & 0.347 \\
\hline Current osteoporosis $(\%)^{\dagger}$ & 44.0 & 39.3 & 0.527 \\
\hline Current arthritis $(\%)^{\dagger}$ & 32.2 & 30.8 & 0.622 \\
\hline Current depression $(\%)^{\dagger}$ & 29.5 & 25.9 & 0.685 \\
\hline History of cancer $(\%)^{\dagger}$ & 16.7 & 21.4 & 0.546 \\
\hline
\end{tabular}

$\mathrm{BMI}=$ body mass index, $\mathrm{C}-\mathrm{RP}=\mathrm{C}$-reactive protein, $\mathrm{HC}=$ hip circumference, MMSE $=$ Mini Mental State Examination, $\mathrm{TC}=$ total cholesterol, $\mathrm{TG}=$ triglycerides, $\mathrm{HbA1c}=$ glycated hemoglobin Alc, $S A H=$ systemic arterial hypertension, $\mathrm{WC}=$ waist circumference, and $\mathrm{W}$-H $=$ waist-to-hip. ${ }^{*} t$-test for independent samples, data as mean and standard deviation. ${ }^{* *}$ Nonparametric test of Mann-Whitney, data as median and interquartile range. ${ }^{\dagger} \mathrm{Chi}-\mathrm{square}$ test, data as within-group proportions.

TABLE 2: Correlation analysis of the immune mediators with anthropometric and metabolic characteristics in a whole-group approach $(n=161)$.

\begin{tabular}{|c|c|c|c|c|c|c|}
\hline & \multicolumn{6}{|c|}{ Log-transformed scores } \\
\hline & $\mathrm{TNF} \alpha$ & $\mathrm{IFN} \gamma$ & IL-10 & IL-6 & IL-4 & IL-2 \\
\hline BMI $\left(\mathrm{kg} \cdot \mathrm{m}^{-2}\right)$ & $0.116 ; 0.179$ & $-0.051 ; 0.549$ & $-0.065 ; 0.442$ & $0.025 ; 0.774$ & $0.141 ; 0.092$ & $-0.035 ; 0.658$ \\
\hline Body fat (\%) & $0.168 ; 0.051$ & $-0.057 ; 0.503$ & $0.070 ; 0.405$ & $0.033 ; 0.702$ & $0.078 ; 0.354$ & $-0.036 ; 0.656$ \\
\hline $\mathrm{W}-\mathrm{H}$ ratio $(\mathrm{cm})$ & $0.137 ; 0.128$ & $-0.058 ; 0.508$ & $-0.157 ; 0.072$ & $0.184 ; 0.038^{*}$ & $0.152 ; 0.081$ & $-0.051 ; 0.543$ \\
\hline Glucose (mg/dL) & $-0.067 ; .439$ & $0.072 ; 0.390$ & $-0.054 ; .519$ & $-0.212 ; 0.012^{*}$ & $-0.045 ; 0.593$ & $0.066 ; 0.405$ \\
\hline $\mathrm{TC}\left(\mathrm{mg} \cdot \mathrm{dl}^{-1}\right)$ & $-0.043 ; 0.619$ & $-0.118 ; 0.162$ & $-0.080 ; 0.344$ & $0.068 ; 0.427$ & $-0.012 ; 0.888$ & $-0.153 ; 0.053$ \\
\hline HDL-c (mg.dl $\left.{ }^{-1}\right)$ & $-0.115 ; 0.181$ & $-0.047 ; 0.581$ & $0.068 ; 0.421$ & $-0.157 ; 0.066$ & $-0.050 ; 0.556$ & $-0.071 ; 0.371$ \\
\hline LDL-c $\left(\mathrm{mg}^{\circ} \cdot \mathrm{dl}^{-1}\right)$ & $-0.024 ; 0.784$ & $-0.063 ; 0.455$ & $-0.072 ; 0.390$ & $0.106 ; 0.215$ & $0.009 ; 0.917$ & $-0.132 ; 0.094$ \\
\hline $\mathrm{TG}\left(\mathrm{mg} \cdot \mathrm{dl}^{-1}\right)$ & $0.085 ; 0.323$ & $-0.127 ; 0.130$ & $-0.129 ; 0.124$ & $0.073 ; 0.396$ & $-0.016 ; 0.854$ & $-0.075 ; 0.347$ \\
\hline C-RP $\left(\mathrm{mg}^{\left.-\mathrm{dl}^{-1}\right)}\right.$ & $-0.008 ; 0.931$ & $0.058 ; 0.510$ & $0.096 ; 0.272$ & $0.223 ; 0.011^{*}$ & $0.024 ; 0.786$ & $-0.035 ; 0.675$ \\
\hline $\operatorname{HbA1c}\left(\mathrm{mg}^{\left.-\mathrm{dl}^{-1}\right)}\right.$ & $0.029 ; 0.760$ & $0.008 ; 0.925$ & $-0.038 ; 0.650$ & $-0.067 ; 0.432$ & $0.026 ; 0.759$ & $0.005 ; 0.905$ \\
\hline AM (qty) & $-0.031 ; 0.742$ & $-0.051 ; 0.579$ & $0.000 ; 0.997$ & $-0.038 ; 0.687$ & $-043 ; 0.640$ & $0.010 ; 0.905$ \\
\hline
\end{tabular}

The Pearson correlation tests were used. Data are expressed in correlation index and significance level $(r ; P) .{ }^{*}$ The correlation is significant in the level of 0.05 . $\mathrm{AM}=$ amount of medicines, $\mathrm{BMI}=$ body mass index, $\mathrm{C}-\mathrm{RP}=\mathrm{C}$-reactive protein, HbAlc $=$ glycated hemoglobin $\mathrm{Alc}, \mathrm{TC}=$ total cholesterol, $\mathrm{TG}=$ triglycerides, and $\mathrm{W}-\mathrm{H}=$ waist-to-hip.

same trait within nonfrail limits, regardless of the associations of $\mathrm{W}-\mathrm{H}$ ratio, glycemia, and C-RP with levels of the cytokine (Table 3). According to this univariate approach, no other component of the frailty syndrome (nor the entire phenotype) was associated with inflammatory variables.
As confirmatory analysis, a multivariate model was tested with variables to which $p<0.20$ was obtained (C-RP and IL-6 for grip strength and only IL-6 for walking time), and it was verified that elderly people with reduced grip strength were 3 times more likely of presenting augmented 
TABLE 3: Univariate binary logistic regression analyses in a wholegroup approach $(n=161)$.

\begin{tabular}{lcccccc}
\hline & \multicolumn{6}{c}{ Frailty component } \\
& \multicolumn{3}{c}{ Low grip strength } & \multicolumn{3}{c}{ High walk time } \\
& OR & CI (95\%) & $p$ & OR & CI (95\%) & $p$ \\
\hline $\begin{array}{l}\text { W-H ratio } \\
(\mathrm{cm})\end{array}$ & 1.47 & $0.04-46.54$ & 0.825 & 5.88 & $0.04-726.99$ & 0.471 \\
$\begin{array}{l}\text { Glucose } \\
(\mathrm{mg} / \mathrm{dL})\end{array}$ & 1.01 & $0.99-1.03$ & 0.254 & 0.98 & $0.96-1.00$ & 0.221 \\
$\begin{array}{l}\mathrm{C}-\mathrm{RP} \\
\left(\mathrm{mg} . \mathrm{dl}^{-1}\right)\end{array}$ & 0.69 & $0.46-1,03$ & 0.070 & 1.10 & $0.73-1.65$ & 0.646 \\
Log IL-6 & 4.68 & $1.59-13.78$ & 0.005 & 2.29 & $0.87-6.04$ & 0.093 \\
\hline
\end{tabular}

$\mathrm{CI}=$ confidence interval, $\mathrm{C}$ - $\mathrm{RP}=\mathrm{C}$-reactive protein, $\log =$ logarithmically transformed, and $\mathrm{OR}=$ odds ratio.

levels of $I L-6\left[\chi^{2}(2)=8.214 ; p=0.016, R^{2}=0.085\right]$ when compared to the nonfrail participants $(\mathrm{OR}=3.299 ; 95 \% \mathrm{CI}$ $1.08-6.09 ; p=0.014)$, while the same was not observed for C-RP (OR $=0.734 ; 95 \%$ CI $0.51-1.07 ; p=0.107)$. Elderly people with high walking time were 2.5 times more likely $\left[\chi^{2}(1)=5.897 ; p=0.015, R^{2}=0.060\right]$ to have circulating $I L$ 6 at levels significantly higher than those found in the very old nonfrail examined participants $(\mathrm{OR}=2.460 ; 95 \% \mathrm{CI}$ $1.16-7.05 ; p=0.022$ ).

\section{Discussion}

The present study aimed to investigate the individual association of each component of Fried's frailty syndrome (and of the phenotype as one) with total serum levels of a set of inflammatory mediators evaluated in a sample of very old Brazilian patients devoid of major cognitive decline cases. As an initial result, an exploratory analysis revealed that only reduced scores of grip strength associated with higher levels of serum $I L-6$. Confirmatory analyses not only reassured the negative correlation between $I L-6$ and hand grip strength (regardless of covariates) but also revealed a similar relationship between walking time scores and the mediator.

Inflammatory mediators emerged as important surrogate markers for performance in traits linked to the skeletal muscle during the aging process [46-50], with evidence for a strong association of supraphysiological concentrations of IL-6 with loss of physical functioning [51]. Interestingly, these findings are independent either of current use of antiinflammatory drugs or of other comorbidities [51]. It no longer surprises that age-related chronic conditions are often characterized by a low-grade augmentation of circulating titers of proinflammatory mediators, which includes IL-6 [52]. But, it remains debatable to which phenotype(s) these idiopathic imbalances in systemic mediators impact the most.

In line, the mechanisms involved in declines of strength and integrity of the skeletal muscle with age and participation of immune signals are still not well understood [53]. Reports repeatedly demonstrate that myofiber atrophy comes from reduced protein synthesis and exacerbated protein catabolism, the latter mainly due to cytoplasmic (ubiquitin-proteosome system) and vesicular (autophagy) protein degradation mechanisms $[54,55]$. So far, some evidence points to proinflammatory interleukins as regulators of these pathways [56-61].

There is growing evidence that chronic IL-6 exposure directly stimulates muscle wasting by activating the ubiquitin-proteosome pathway, which in turn destroys cytosolic and nuclear proteins in fiber cells $[58,59]$, with implications for physical performance. Moreover, evidence shows that $I L$ 6 action on muscle includes activation of the signal transducer and activator of transcription 3 (STAT3) [62-64], a fundamental autophagy regulator stored in the cytosol whose translocation to the cell nucleus occurs upon phosphorization to bind to specific DNA elements. STAT3 is known to activate proautophagic effector genes as those for the protein-interacting protein 3 (BNIP3) and the hypoxiainducible factor (HIF1A) [65, 66] and other downstream regulators of the autophagic process such as the transcription factors FOXO1 and FOXO3 $[67,68]$ which in turn increases expression of a myriad of other genes that execute autophagy in the cell. Furthermore, there is evidence that $I L$ 6 stimulates the adrenal-pituitary axis, causing release of ACTH that increases circulating levels of cortisol, impairing synthesis in the striated muscles $[56,57]$. Thus, our finding corroborates the hypothesis that even slightly augmented levels of $I L-6$ can possibly produce effects that predispose to the physical phenotype of frailty.

The authors do not intend to drive the readers' sight away from studies with an approach similar to ours or from the fact that our findings resemble those reported elsewhere. On our behalf, our report places a contribution by specifically investigating the subset of low-functioning very old adults, while most of the literature that evaluates immune mediators (intended as biomarkers for frailty) across performance levels simply addresses older individuals in general and usually includes high-functioning individuals [61, 69]. Regardless that the physical performance scores herein assessed were statistically different across frail and nonfrail individuals, it is noteworthy that mean measures were far from different in terms of clinical relevance. Accordingly, no single score of hand grip strength or walking time was greater than $25 \mathrm{kgf}$ or lower than $4 \mathrm{~s}$, respectively, which is compatible with an overall status of poor physical functioning.

Despite the cross-sectional design and the limited sampling, this study has strengths in the sense that some level of homogeneity was possible when recruiting participants for analyses, with all very old adults devoid of major cognitive impairments, so to rule out possible disabilities owing to cases of dementia. Moreover, it was possible to detect and control covariates related to $I L-6$ prior to obtaining the main outputs described herein, allowing to assume that spurious associations were unlikely in the scenario. At last, assessing at once several mediators that notably demonstrate extraimmunological effects would reduce partialities related to addressing "favorite players" only, also known as the positive publication bias around IL-6.

\section{Conclusions}

Our study shows a strong negative association of circulating levels of $I L-6$ with levels of hand grip strength and of walking 
time assessed according to Fried's frailty phenotype among very old individuals.

\section{Data Availability}

The data supporting the current study can be made available from the corresponding author upon reasonable request.

\section{Ethical Approval}

All procedures performed in studies involving human participants were in accordance with ethical standards of the institution and/or national research committee (Ethics Committee on Research, Catholic University of Brasília) and with the 1964 Helsinki Declaration and its later amendments or comparable ethical standards.

\section{Conflicts of Interest}

The authors declare that there are no conflicts of interest.

\section{Acknowledgments}

The authors thank the administrative office of the Hospital of Catholic University of Brasilia for the environment, for the clinical testing, and assessments, the Biology Institute of the University of Brasília for access to the FACS Verse ${ }^{\mathrm{TM}}$ cytometer and due infrastructure, and to the Sabin Institute in Brasília for the clinical biochemistry assessments. This work was supported by Fundação de Amparo à Pesquisa do Distrito Federal (FAP-DF, grant \# 193.000.997/2015) and by the Coordenação de Aperfeiçoamento de Pessoal de Nível Superior (CAPES, FinanceCode 001 and grant \# 2972/2014).

\section{References}

[1] R. Z. Megale, M. L. Ferreira, P. H. Ferreira et al., "Association between pain and the frailty phenotype in older men: longitudinal results from the Concord Health and Ageing in Men Project (CHAMP)," Age and Ageing, vol. 47, no. 3, pp. 381-387, 2018.

[2] G. S. Morais Junior, V. C. Souza, W. Machado-Silva et al., "Resistance training modulates the humoral inflammatory (but not the DNA methylation) profile of diabetic older adults using metformin," Neuroimmunomodulation, vol. 26, pp. 1-8, 2019.

[3] D. Scott, M. Seibel, R. Cumming et al., "Sarcopenic obesity and its temporal associations with changes in bone mineral density, incident falls, and fractures in older men: the concord health and ageing in men project," Journal of Bone and Mineral Research, vol. 32, no. 3, pp. 575-583, 2017.

[4] L. P. Fried, C. M. Tangen, J. Walston et al., "Frailty in older adults: evidence for a phenotype," Journals of Gerontology. Series A, Biological Sciences and Medical Sciences, vol. 56, no. 3, pp. 146-156, 2001.

[5] N. R. S. Pivetta, J. C. S. Marincolo, A. L. Neri, I. Aprahamian, M. S. Yassuda, and F. S. A. Borim, "Multimorbidity, frailty and functional disability in octogenarians: a structural equation analysis of relationship," 9Archives of Gerontology and Geriatrics, vol. 86, Article ID 103931, 2019.

[6] D. Rizzuto, R. J. F. Melis, S. Angleman, C. Qiu, and A. Marengoni, "Effect of chronic diseases and multimorbidity on survival and functioning in elderly adults," Journal of the American Geriatrics Society, vol. 65, no. 5, pp. 1056-1060, 2017.

[7] D. L. Vetrano, A. Calderón-Larrañaga, A. Marengoni et al., "An international perspective on chronic multimorbidity: approaching the elephant in the room," The Journals of Gerontology: Series A, vol. 73, no. 10, pp. 1350-1356, 2018.

[8] P. Abizanda, L. Romero, P. M. Sánchez-Jurado, M. MartínezReig, S. A. Alfonso-Silguero, and L. Rodríguez-Mañas, "Age, frailty, disability, institutionalization, multimorbidity or comorbidity. Which are the main targets in older adults?" The Journal of Nutrition, Health \& Aging, vol. 18, no. 6, pp. 622-627, 2014.

[9] C. Hall, S. Essler, J. Dandashi et al., "Impact of frailty and anticoagulation status on readmission and mortality rates following falls in patients over 80," Baylor University Medical Center Proceedings, vol. 32, no. 2, pp. 181-186, 2019.

[10] X. Chen, G. Mao, and S. X. Leng, "Frailty syndrome: an overview," Clinical Interventions in Aging, vol. 9, pp. 433-441, 2014.

[11] G. Pawelec, A. Bronikowski, S. C. Cunnane et al., "The conundrum of human immune system "senescence"," Mechanisms of Ageing and Development, vol. 192, Article ID 111357, 2020.

[12] L. Zuo, E. R. Prather, M. Stetskiv et al., "Inflammaging and oxidative stress in human diseases: from molecular mechanisms to novel treatments," International Journal of Molecular Sciences, vol. 20, no. 18, 2019.

[13] L. A. Robinson and C. M. Pierce, "Is "inflammaging" fuelling severe COVID-19 disease?" Journal of the Royal Society of Medicine, vol. 113, no. 9, pp. 346-349, 2020.

[14] M. Michaud, L. Balardy, G. Moulis et al., "Proinflammatory cytokines, aging, and age-related diseases," Journal of the American Medical Directors Association, vol. 14, no. 12, pp. 877-882, 2013.

[15] D. Draganidis, L. G. Karagounis, I. Athanailidis, A. Chatzinikolaou, A. Z. Jamurtas, and I. G. Fatouros, "Inflammaging and skeletal muscle: can protein intake make a difference?" The Journal of Nutrition, vol. 146, no. 10, pp. 1940-1952, 2016.

[16] P. Soysal, B. Stubbs, P. Lucato et al., "Inflammation and frailty in the elderly: a systematic review and meta-analysis," Ageing Research Reviews, vol. 31, pp. 1-8, 2016.

[17] N. S. Yarla, A. Polito, and I. Peluso, "Effects of olive oil on TNF-alpha and IL-6 in humans: implication in obesity and frailty," Endocr Metab Immune Disord Drug Targets, vol. 18, no. 1, pp. 63-74, 2018.

[18] C. M. C. Nascimento, M. S. Zazzetta, G. A. O. Gomes et al., "Higher levels of tumor necrosis factor beta are associated with frailty in socially vulnerable community-dwelling older adults," BMC Geriatrics, vol. 18, no. 1, p. 268, 2018.

[19] T. Juarez-Cedillo, G. Vargas-Alarcon, N. Martinez-Rodriguez, E. Juarez-Cedillo, and J. M. Fragoso, "Escobedo-de-laPena J. Interleukin 10 gene polymorphisms and frailty syndrome in elderly Mexican people: (Sadem study)," Molecular Genetics \& Genomic Medicine, vol. 7, no. 9, p. e918, 2019.

[20] G. A. Langmann, S. Perera, M. A. Ferchak, D. A. Nace, N. M. Resnick, and S. L. Greenspan, "Inflammatory markers and frailty in long-term care residents," Journal of the American Geriatrics Society, vol. 65, no. 8, pp. 1777-1783, 2017.

[21] T. G. Pérez-Suárez, L. M. Gutiérrez-Robledo, J. A. ÁvilaFunes et al., "VNTR polymorphisms of the IL-4 and IL-1RN genes and their relationship with frailty syndrome in Mexican 
community-dwelling elderly," Aging Clinical and Experimental Research, vol. 28, no. 5, pp. 823-832, 2016.

[22] G. Bano, C. Trevisan, S. Carraro et al., "Inflammation and sarcopenia: a systematic review and meta-analysis," Maturitas, vol. 96, pp. 10-15, 2017.

[23] A. L. Bian, H. Y. Hu, Y. D. Rong, J. Wang, J. X. Wang, and X. Z. Zhou, "A study on relationship between elderly sarcopenia and inflammatory factors IL-6 and TNF-alpha," European Journal of Medical Research, vol. 22, no. 1, p. 25, 2017.

[24] A. B. Newman, J. S. Gottdiener, M. A. Mcburnie et al., "Associations of subclinical cardiovascular disease with frailty," The Journals of Gerontology Series A: Biological Sciences and Medical Sciences, vol. 56, no. 3, pp. M158-M166, 2001.

[25] Y. D. Rong, A. L. Bian, H. Y. Hu, Y. Ma, and X. Z. Zhou, "Study on relationship between elderly sarcopenia and inflammatory cytokine IL-6, anti-inflammatory cytokine IL-10," BMC Geriatrics, vol. 18, no. 1, p. 308, 2018.

[26] P.-O. Lang, J.-P. Michel, and D. Zekry, "Frailty syndrome: a transitional state in a dynamic process," Gerontology, vol. 55, no. 5, pp. 539-549, 2009.

[27] C. R. Gale, C. N. Martyn, C. Cooper, and A. A. Sayer, "Grip strength, body composition, and mortality," International Journal of Epidemiology, vol. 36, no. 1, pp. 228-235, 2007.

[28] D. Goldeck, G. Pawelec, K. Norman et al., "No strong correlations between serum cytokine levels, CMV serostatus and hand-grip strength in older subjects in the Berlin BASE-II cohort," Biogerontology, vol. 17, no. 1, pp. 189-198, 2016.

[29] A. H. Kilgour, C. Firth, R. Harrison et al., "Seropositivity for CMV and IL-6 levels are associated with grip strength and muscle size in the elderly," Immun Ageing, vol. 10, no. 1, p. 33, 2013.

[30] D. Legrand, W. Adriaensen, B. Vaes, C. Matheï, P. Wallemacq, and J. Degryse, “The relationship between grip strength and muscle mass (MM), inflammatory biomarkers and physical performance in community-dwelling very old persons," Archives of Gerontology and Geriatrics, vol. 57, no. 3, pp. 345-351, 2013.

[31] S. Baldi, C. Bruschi, R. Maestri et al., "The mediating role of cytokine IL-6 on the relationship of FEV1 upon 6-minute walk distance in chronic obstructive pulmonary disease," International Journal of Chronic Obstructive Pulmonary Disease, vol. 9, pp. 1091-1099, 2014.

[32] L. Ma, G. Sha, Y. Zhang, and Y. Li, "Elevated serum IL-6 and adiponectin levels are associated with frailty and physical function in Chinese older adults," Clinical Interventions in Aging, vol. 13, pp. 2013-2020, 2018.

[33] V. M. Pinto-Plata, C. Cote, H. Cabral, J. Taylor, and B. R. Celli, "The 6-min walk distance: change over time and value as a predictor of survival in severe COPD," European Respiratory Journal, vol. 23, no. 1, pp. 28-33, 2004.

[34] J. C. Silva, Z. V. de Moraes, C. Silva et al., "Understanding red blood cell parameters in the context of the frailty phenotype: interpretations of the FIBRA (Frailty in Brazilian Seniors) study," Archives of Gerontology and Geriatrics, vol. 59, no. 3, pp. 636-641, 2014.

[35] L. Ferrucci, J. M. Guralnik, S. Studenski et al., "Designing randomized, controlled trials aimed at preventing or delaying functional decline and disability in frail, older persons: a consensus report," Journal of the American Geriatrics Society, vol. 52, no. 4, pp. 625-634, 2004.
[36] R. Jardim, S. M. Barreto, and L. Giatti, "Auto-relato e relato de informante secundário na avaliação da saúde em idosos," Revista de Saúde Pública, vol. 44, no. 6, pp. 1120-1129, 2010.

[37] R. Nitrini, P. Caramelli, C. M. d. C. Bottino, B. P. Damasceno, S. M. D. Brucki, and R. Anghinah, "Diagnóstico de doença de Alzheimer no Brasil: critérios diagnósticos e exames complementares. Recomendações do Departamento Científico de Neurologia Cognitiva e do Envelhecimento da Academia Brasileira de Neurologia," Arquivos de Neuro-Psiquiatria, vol. 63, no. 3a, pp. 713-719, 2005.

[38] World Health Organization, Physical Status: The Use and Interpretation of Anthropometry, pp. 1-452, World Health Organization, Geneva, Switzerland, 1995.

[39] M. Scartezini, C. E. D. S. Ferreira, M. C. O. Izar et al., "Positioning about the flexibility of fasting for lipid profiling," Arquivos brasileiros de cardiologia, vol. 108, no. 3, pp. 195-197, 2017.

[40] L. P. Lustosa, D. S. Pereira, R. C. Dias, R. R. Britto, A. N. Parentoni, and L. S. M. Pereira, "Translation and cultural adaptation of the Minnesota Leisure Time Activities Questionnaire in community-dwelling older people," Geriatr Gerontol Aging, vol. 5, no. 2, pp. 57-65, 2011.

[41] L. S. Radloff, "The CES-D scale," Applied Psychological Measurement, vol. 1, no. 3, pp. 385-401, 1977.

[42] J. A. Dias, A. C. Ovando, W. Külkamp, and N. G. Borges Junior, "Hand grip strength: evaluation methods and factors influencing this measure," Revista Brasileira de Cineantropometria \& Desempenho Humano, vol. 12, pp. 209-216, 2010.

[43] J. M. Guralnik, E. M. Simonsick, L. Ferrucci et al., "A short physical performance battery assessing lower extremity function: association with self-reported disability and prediction of mortality and nursing home admission," Journal of Gerontology, vol. 49, no. 2, pp. 85-94, 1994.

[44] T. B. Costa and A. L. Neri, "Indicators of physical activity and frailty in the elderly: data from the FIBRA study in Campinas, São Paulo State, Brazil," Cad Saude Publica, vol. 27, no. 8, pp. 1537-1550, 2011.

[45] A. L. Neri, M. S. Yassuda, L. F. d. Araújo et al., "Metodologia e perfil sociodemográfico, cognitivo e de fragilidade de idosos comunitários de sete cidades brasileiras: estudo FIBRA," Cadernos de Saúde Pública, vol. 29, no. 4, pp. 778-792, 2013.

[46] A. J. Cruz-Jentoft, J. P. Baeyens, J. M. Bauer et al., "Sarcopenia: European consensus on definition and diagnosis: report of the European working group on sarcopenia in older people," Age and Ageing, vol. 39, no. 4, pp. 412-423, 2010.

[47] T.-T. Dam, K. W. Peters, M. Fragala et al., "An evidence-based comparison of operational criteria for the presence of sarcopenia," The Journals of Gerontology Series A: Biological Sciences and Medical Sciences, vol. 69, no. 5, pp. 584-590, 2014.

[48] L. Ferrucci, B. W. J. H. Penninx, S. Volpato et al., "Change in muscle strength explains accelerated decline of physical function in older women with high interleukin-6 serum levels," Journal of the American Geriatrics Society, vol. 50, no. 12, pp. 1947-1954, 2002.

[49] F.-C. Hsu, S. B. Kritchevsky, Y. Liu et al., "Association between inflammatory components and physical function in the health, aging, and body composition study: a principal component analysis approach," The Journals of Gerontology Series A: Biological Sciences and Medical Sciences, vol. 64A, no. 5, pp. 581-589, 2009.

[50] L. P. Lustosa, L. S. Máximo Pereira, F. M. Coelho et al., "Impact of an exercise program on muscular and functional 
performance and plasma levels of interleukin 6 and soluble receptor tumor necrosis factor in prefrail communitydwelling older women: a randomized controlled trial," Archives of Physical Medicine and Rehabilitation, vol. 94, no. 4, pp. 660-666, 2013.

[51] D. de Gonzalo-Calvo, B. de Luxán-Delgado, S. RodríguezGonzález et al., "Interleukin 6, soluble tumor necrosis factor receptor I and red blood cell distribution width as biological markers of functional dependence in an elderly population: a translational approach," Cytokine, vol. 58, no. 2, pp. 193-198, 2012.

[52] L. Lustosa, P. Batista, D. Pereira, L. Souza Maximo Pereira, A. Scianni, and G. Ribeiro-Samora, "Comparison between parameters of muscle performance and inflammatory biomarkers of non-sarcopenic and sarcopenic elderly women," Clinical Interventions in Aging, vol. 12, pp. 1183-1191, 2017.

[53] F. Demontis, R. Piccirillo, A. L. Goldberg, and N. Perrimon, "Mechanisms of skeletal muscle aging: insights from Drosophila and mammalian models," Disease Models \& Mechanisms, vol. 6, no. 6, pp. 1339-1352, 2013.

[54] P. Bonaldo and M. Sandri, "Cellular and molecular mechanisms of muscle atrophy," Disease Models \& Mechanisms, vol. 6, no. 1, pp. 25-39, 2013.

[55] R. Piccirillo, F. Demontis, N. Perrimon, and A. L. Goldberg, "Mechanisms of muscle growth and atrophy in mammals andDrosophila," Developmental Dynamics, vol. 243, no. 2, pp. 201-215, 2014.

[56] C. Cray, J. Zaias, and N. H. Altman, "Acute phase response in animals: a review," Comparative Medicine, vol. 59, no. 6, pp. 517-526, 2009.

[57] E. Gruys, M. J. M. Toussaint, T. A. Niewold, and S. J. Koopmans, "Acute phase reaction and acute phase proteins," Journal of Zhejiang University Science, vol. 6B, no. 11, pp. 1045-1056, 2005.

[58] J. Khal, S. M. Wyke, S. T. Russell, A. V. Hine, and M. J. Tisdale, "Expression of the ubiquitin-proteasome pathway and muscle loss in experimental cancer cachexia," British Journal of Cancer, vol. 93, no. 7, pp. 774-780, 2005.

[59] S. H. Lecker, A. L. Goldberg, and W. E. Mitch, "Protein degradation by the ubiquitin-proteasome pathway in normal and disease states," Journal of the American Society of $\mathrm{Ne}$ phrology, vol. 17, no. 7, pp. 1807-1819, 2006.

[60] L. A. Schaap, S. M. Pluijm, D. J. Deeg, and M. Visser, "Inflammatory markers and loss of muscle mass (sarcopenia) and strength," American Journal of Medicine, vol. 119, no. 6, pp. 526 e9-526 e17, 2006.

[61] D. R. Taaffe, T. B. Harris, L. Ferrucci, J. Rowe, and T. E. Seeman, "Cross-sectional and prospective relationships of interleukin-6 and C-reactive protein with physical performance in elderly persons: MacArthur studies of successful aging," The Journals of Gerontology Series A: Biological Sciences and Medical Sciences, vol. 55, no. 12, pp. M709-M715, 2000.

[62] P. Maycotte, C. M. Gearheart, R. Barnard et al., "STAT3mediated autophagy dependence identifies subtypes of breast cancer where autophagy inhibition can be efficacious," Cancer Research, vol. 74, no. 9, pp. 2579-2590, 2014.

[63] S. Shen, M. Niso-Santano, S. Adjemian et al., "Cytoplasmic STAT3 represses autophagy by inhibiting PKR activity," Molecular Cell, vol. 48, no. 5, pp. 667-680, 2012.

[64] L. You, Z. Wang, H. Li et al., "The role of STAT3 in autophagy," Autophagy, vol. 11, no. 5, pp. 729-739, 2015.
[65] N. M. Mazure and J. Pouysségur, "Hypoxia-induced autophagy: cell death or cell survival?" Current Opinion in Cell Biology, vol. 22, no. 2, pp. 177-180, 2010.

[66] J. Pratt and B. Annabi, "Induction of autophagy biomarker BNIP3 requires a JAK2/STAT3 and MT1-MMP signaling interplay in Concanavalin-A-activated U87 glioblastoma cells," Cellular Signalling, vol. 26, no. 5, pp. 917-924, 2014.

[67] C. Mammucari, G. Milan, V. Romanello et al., "FoxO3 controls autophagy in skeletal muscle in vivo," Cell Metabolism, vol. 6, no. 6, pp. 458-471, 2007.

[68] H.-M. Oh, C.-R. Yu, I. Dambuza, B. Marrero, and C. E. Egwuagu, "STAT3 protein interacts with class O forkhead transcription factors in the cytoplasm and regulates nuclear/cytoplasmic localization of FoxO1 and FoxO3a proteins in CD4+T cells," Journal of Biological Chemistry, vol. 287, no. 36, pp. 30436-30443, 2012.

[69] C. Custodero, S. D. Anton, D. P. Beavers et al., "The relationship between interleukin-6 levels and physical performance in mobility-limited older adults with chronic lowgrade inflammation: the ENRGISE Pilot study," Archives of Gerontology and Geriatrics, vol. 90, Article ID 104131, 2020. 